\title{
Evidence for the Brief Mysticism Scale: Psychometric Properties, and Moderation and Mediation Effects in Predicting Spiritual Self-identification
}

\author{
Heinz Streib ${ }^{1}$ and Zhuo Job Chen ${ }^{2}$ \\ ${ }^{1}$ Bielefeld University, Germany \\ ${ }^{2}$ Department of Psychology, Clemson University
}

\begin{abstract}
Author Note
Data used in this study were collected in research projects that have been funded by grants from the German Research Foundation (Deutsche Forschungsgemeinschaft) and the John Templeton Foundation (JTF). Analyses are part of the current JTF Project (ID \#60806). We have no conflicts of interest to disclose.

Correspondence concerning this article should be addressed to Heinz Streib, Center for Biographical Studies in Contemporary Religion, Bielefeld University, Post Box 100131, D-33501 Bielefeld, Germany, Email: Heinz.Streib@uni-bielefeld.de.
\end{abstract}




\begin{abstract}
How are mystical experiences related to self-rated spirituality? Is the recently developed short 8-item version of Hood's (1975) Mysticism Scale an efficient measurement? The current study expands evidence for both questions using $N=1,582$ American and $N=1,492$ German samples measured in three waves, average 4 to 5 years apart. Results show that the 8-item brief M-Scale has good psychometric property evidenced by 1) measurement invariance across time, and 2) good test-retest reliability. Results further demonstrate that the 8-item brief M-Scale 3) moderates the effect of self-rated religiosity on self-rated spirituality, and 4) mediates the prediction of self-rated religiosity on self-rated spirituality over time. We conclude that the MScale can be used as a measure for self-attributed spirituality and that the 8-item brief version of the M-Scale can be used when questionnaire length is an issue.
\end{abstract}

Keywords: mysticism; spirituality; Mysticism Scale; religiosity; mediation; moderation 


\section{Introduction}

For the preparation of a first cooperative research project, the Deconversion Project, some twenty years ago, Ralph Hood was visiting with the first author, who still remembers his big astonishment when Ralph Hood suggested including in the questionnaire a measure for spirituality—unheard of in German research at that time. Thus, thanks to Ralph Hood, this questionnaire was, to our knowledge, the first to assess self-identified spirituality in Germany. And the results already from a pilot test with first-year students at the University of Tennessee at Chattanooga and Bielefeld University (Streib, 2005) and later the main Deconversion Study (Streib et al., 2009) revealed considerable popularity of self-attributed spirituality not only in the United States but also in Germany. It was these high numbers of "more spiritual" respondents, even doubling in the deconvert sample, that strongly suggested engaging in another project investigating the semantics and psychology of spirituality (Streib \& Hood, 2016b), which—again an innovation for research in Germany-included Hood's (1975) Mysticism Scale (M-Scale) in full length. This is but one instance of inspiring cooperation and friendship that continued and developed over the years. And this article is also a way to say thanks and honor Ralph Hood's contribution to research in the psychology of religion that included reaching out to Germany.

This paper reports analyses of the relation of mysticism and self-rated spirituality using the recently developed brief, 8-item version of Hood's (1975) M-Scale (Streib et al., 2020). In a first round of analyses, measurement invariance and test-retest reliability for this brief M-Scale are estimated using three-wave longitudinal data. 


\section{A Brief History of the Mysticism Scale}

Hood's (1975) construction of the M-scale is not only deeply rooted in James' (1902) account of mysticism, but it also clearly reflects the phenomenology of mysticism presented by Stace (1960). Hood developed the M-scale based upon Stace's (1960) universal core model. The M-scale, which over the decades has become the most widely used measure of mysticism, has emerged to yield robust empirical confirmation of Stace's phenomenological model in both exploratory and confirmatory factor analytic studies (Hood et al., 2018). Factor analysis has demonstrated a three-factor solution for the M-scale (Hood et al., 1993) that includes:

(a) introvertive mysticism, which consists of items related to the aspects (facets) timelessness and spacelessness, ego loss, and ineffability,

(b) extrovertive mysticism, which consists of items of inner subjectivity and unity,

(c) interpretation of mysticism, which consists of items associated with the three aspects of positive affect, sacredness, and noetic quality.

This three-factor solution of the M-Scale has been replicated in a variety of cultures: This includes Iranian Muslim samples (Hood et al., 2001), Jewish samples in Israel (Lazar \& Kravetz, 2005), Chinese samples including Christians and Buddhist monks and nuns (Chen, Hood et al., 2011; Chen, Qi et al., 2011; Chen, Zhang et al., 2012), and an Indian sample including Hindus, Muslims, and Christians (Anthony et al., 2010). The three-factor structure of the M-scale has also been corroborated in the Study on Spirituality (Klein et al., 2016).

Recently, Streib et al. (2020) developed a short version of the M-scale. This short version consists of a selection of eight items—one item for each facet. All items were selected from Hood's (1975) original 32-item M-scale (for the wording of items, see Table 2). Streib et al. (2020) could demonstrate initial evidence for the three-factor structure of this brief M-Scale and for its retest reliability based on two-wave data. 


\section{Spirituality and Mysticism}

The M-scale is a classic measure for mystical experiences, which had been developed long before spirituality became a popular self-attribution in the U.S.A. and, with some delay, also in the Germany — and long before spirituality attracted the attention of researchers in the empirical study of religion. That mysticism is, besides the churches (priests) and sects (prophets), a third magnetic pole in the religious field, can be claimed with reference to Troeltsch's (1912) sociology of religion. Troeltsch argued that the third actor in the religious field that in Weber's (1921) and Bourdieu’s (1971a, 1971b) model were the magicians are in fact the mystics. And mysticism, according to Troeltsch, can be part of organized religion, but can also take place outside the churches as "unchurched mysticism" and thus describe the location of the "not religious, but spiritual" people today (Daiber, 2002). Based on these and other classic contributions, Streib and Hood (2011, 2013, 2016a) conceptualized spirituality as privatized, experience-oriented religion. This view includes the assumption that the more spiritual the individual, the more they see transcendence not necessarily mediated by institutions of priests, systems of belief, established rituals, or belonging to a specific religious organization, nor by the teachings of a charismatic, but the spiritual person experiences transcendence as immediacy to the ultimate. This constitutes an essential relation between spirituality and mysticism.

Empirical research has documented that mysticism has a special relation to spirituality and that the M-scale may have the potential to predict self-rated spirituality. Zinnbauer et al. (1997), for example, studied the relation between items from the M-scale that assess ego-loss and unity experiences and two single items asking whether the participants considered themselves to be spiritual or religious. While mystical experiences did not correlate significantly with self-rated religion $(r=.04)$, the correlation between mystical experiences and self-rated spirituality was found to be significant ( $r=.27$ ). This finding confirms that mystical experiences are not necessarily associated with religion, but rather with the self-identification as being spiritual. 
Further, in a study reported by Hood (2003) using the full M-scale, participants were divided into four groups according to their self-identification as either more religious than spiritual, more spiritual than religious, equally religious and spiritual, or neither religious nor spiritual. The highest levels of mystical experiences were reported by the group of the more spiritual than religious. The important difference was between the two groups which included spirituality in their self-identifications (more spiritual than religious and equally religious and spiritual) in comparison to the two groups which excluded spirituality (more religious than spiritual and neither religious nor spiritual). This finding is consistent with results of Zinnbauer et al. (1997), but it is based on the entire M-Scale. More recently, structural equation modeling using the data from our Study on Spirituality (Streib \& Hood, 2016b) evidenced the relation of the 32-item Mscale with self-rated spirituality (Klein et al., 2016; Streib et al., 2020). This relation could also be corroborated for the new 8-item version of the M-Scale (Streib et al., 2020). However, all of these results are based on cross-sectional data, thus do not yield evidence for the direction of prediction.

\section{Current study}

The current study is a contribution to fill this gap with focus on the 8-item M-scale. Because analyses in the current study could be based on longitudinal three-wave data, they allow the estimation not only of measurement invariance, test-retest reliability, and convergent validity, but also of moderation and mediation of mysticism for self-rated spirituality. The results reported in this article take up the thread of the chapter in which the brief version of the M-scale was introduced and initially validated (Streib et al., 2020), but take these analyses to a higher level by using longitudinal data from three times of measurement. With a special focus on the brief Mscale, these three-wave data allow not only to test new and more ambitious hypotheses about measurement invariance and test-retest reliability, but also about the moderation and mediation effects of the M-Scale, when self-rated religiosity at Time 1 is related to self-rated spirituality at 
Time 3. Here we present the hypotheses for this study:

H1. The 8-item M-scale will show measurement invariance across time. That is, the structure and meaning of the items will hold stable across the three times of measurement.

H2. The 8-item M-scale will show test-retest reliability and positive correlations with selfrated religiosity and spirituality, documenting convergent validity.

H3. Mysticism will moderate the effect of self-rated religiosity on self-rated spirituality. The association between religiosity and spirituality will be weaker among people of higher mysticism.

H4. Mysticism will at least partially mediate the prediction of self-rated religiosity on self- rated spirituality. Religiosity will lead to an increase in mysticism, which in turn will lead to an increase in spirituality.

\section{Method}

\section{Participants}

Analyses are based on a total of $N=3,074\left(n_{U S A}=1,582, n_{G E R}=1,492\right)$ answers to the Mscale (at least to the short version) in the questionnaires of three Bielefeld-based projects:

A. the Bielefeld-Chattanooga Cross-cultural Study on Spirituality (Streib \& Hood, 2016b), for which data collection began in April, 2010 and was completed in May, 2011, when the questionnaire was answered by $N=1,886\left(n_{\text {USA }}=1,113, n_{\text {GER }}=773 ; 60.5 \%\right.$ female, $39.5 \%$ male; $M_{\text {age }}=38.0$, range: 15 to 90 years). This sample is labeled in the following the First Wave or Time 1 (T1).

B. the first phase of a follow-up study on religious development (data collection between May, 2015 and December, 2016), which includes in $N=710$ M-Scale answers $\left(n_{\text {USA }}=254\right.$, $n_{\text {GER }}=456 ; 57,7 \%$ female, $41,4 \%$ male; $M_{\text {age }}=39.1$, range: 16 to 84 years). This sample is 
the Second Wave or Time 2 (T2).

C. the study "Faith Development Revisited” (data collection between September, 2018 and December, 2019) with $N=478$ answers of (at least) the short version of the M-Scale ( $n_{U S A}=$ 215, $n_{\text {GER }}=263 ; 56,3 \%$ female, 43.0 male; $M_{a g e}=46.7$, range: 18 to 86 years). This sample is the Third Wave or Time 3 (T3).

Part of these participants have answered the M-scale in two waves and thus allow for twowave longitudinal estimates as used for testing measurement invariance (H1). Participants with MScale answers at T1 and T2 are: $N=289\left(n_{U S A}=83, n_{\text {GER }}=206 ; 43.9 \%\right.$ female, $51.5 \%$ male; $M_{\text {age(T2) }}$ $=49.5$, range: 23 to 84 years); the sample for T2 and T3 consists of $N=233\left(n_{U S A}=36, n_{G E R}=197\right.$; 53.0\% female, $46.1 \%$ male; $M_{\text {age }(T 3)}=52.8$, range: 19 to 85 years). Three-wave longitudinal cases with (at least) the short version of the M-scale are $N=158\left(n_{U S A}=26, n_{G E R}=132 ; 49.0 \%\right.$ female, 49.7\% male; $M_{\text {age(T3) }}=54.7$, range: 27 to 85 years).

\section{Measures}

For an assessment of mystical experiences, we used Hood's (1975) Mysticism Scale. The development of the brief, 8-item version of the M-scale, is presented by Streib and colleagues (2020). The items in English are presented in Table 2 in this article, the M-Scale items including their German translation is presented by Streib et al. (2020). In the questionnaire a 5- point rating scale has been used, ranging from very inaccurate/definitely not true to very accurate/definitely true. Reliability for the brief version of the M-scale in our three samples was $\alpha_{\mathrm{T} 1}=.86, \alpha_{\mathrm{T} 2}=.88$, and $\alpha_{\mathrm{T} 3}=$ .90. Cronbach's alpha values for the three M-scale factors can be read on the diagonal of Table 3.

For the assessment of how the respondents rate their own religiosity or spirituality, two 5-point self-rating items have been used in all three waves: "How would you describe yourself?" with responses ranging from $1=$ not religious to $5=$ religious and from $1=$ not spiritual to 5 = spiritual. 


\section{Analyses}

To test H1, we conducted confirmatory factor analysis (CFA) using the lavaan package in R. Measurement invariance models fit simultaneous CFA's for the M-scale measured across time. We tested measurement invariance of the mysticism scale between T1 and T2, between T2 and T3, and across T1, T2, and T3.

Measurement invariance analysis tests the degree to which item loadings, intercepts, and residuals of a scale can be held equal across measurement models at different measurement occasions. A sequence of four CFA's with increased levels of constraints will be fit to the data. Configural invariance being the least restrictive level, specifies the measurement model without imposing any equality across time. For instance, to test the measurement invariance of T1 and T2 mysticism, the configural invariance model included six latent variables, three (i.e., introvertive, extrovertive, and interpretive mysticism) for each of the two measurement occasions, their indicators being items measured at that occasion and residuals of the same items correlated with each other. Weak invariance assumes configural invariance and requires equality of the unstandardized loadings. The satisfaction of weak invariances offers evidence for the comparable meaning of items across time. Strong invariance assumes weak invariance and requires equal unstandardized intercepts over time. The satisfaction of strong invariance enables direct comparison of scale scores across time. Strict invariance assumes strong invariance and further requires equality in residual variances across the groups.

Conventional goodness-of-fit cutoffs include comparative fit index (CFI) > .95, root mean squared error $($ RMSEA) $<.06$, and standardized root mean residuals $($ SRMR $)<.08$. A comparison of measurement invariance models is based on changes in CFI and RMSEA. The thresholds for difference in $\mathrm{CFI} \leq .010$ or difference in RMSEA $\leq .015$ would indicate a nonsignificant decrease in model fit between successive measurement invariance models and, as an additional measure, a lower value in BIC favors the model that balances parsimony and goodness- 
of-fit. (Kline, 2016).

H2 was tested based on correlations of scale scores and latent variables. Moderation analysis of $\mathrm{H} 3$ used religiosity $\mathrm{T} 1$ as a predictor, mysticism factors at $\mathrm{T} 2$ as moderators, and spirituality at T3 as an outcome, fully capitalizing on the temporally sequential strength of the data. Visualization of the moderation effects used the ggplot2 package in R. Mediation effect in H4 was evaluated in the context of structural equation modeling with religiosity T1 as a predictor, three T2 mysticism factors simultaneously serving as mediators, and spirituality T3 as an outcome. The indirect effect was statistically tested by the 1000-sample bootstrapped confidence intervals.

\section{Results}

\section{Measurement invariance across time (H1)}

Three sets of measurement invariance models documented the degree to which the 8item M-scale held its structure across time. Each set sequentially tested four models. Table 1 shows the model fit and comparison statistics for these models. The top panel tested measurement invariance across T1 and T2. Model fit statistics were largely in the ballpark of recommended values. Successive comparisons did not indicate a severe model fit decrease with an increase in RMSEA within .015 and a decrease in CFI within .010. Therefore, strict measurement invariance held for the mysticism scale across T1 and T2, suggesting that the loading, intercept, and residual of the indicators could be held equal across these two times of measurement.

Results in the middle and bottom panels were similar, and the bottom panel was the most stringent test across three measurement occasions. Taken together, these results offered strong support for H1, attesting to the stability of the Mysticism Scale administered across time. 
These models, consistent with the traditional conceptualization of mysticism, treated the M-scale as three correlated factors. Table 2 shows the factor loadings of all eight items on the three mysticism factors. These three factors were not independent of each other, as one usually observes moderate to strong positive correlation, in this study, $r$ ranging from .55 to .73 (see Table 3). However, CFA results offered empirical support for the separation of the three factors.

Prior to running the measurement invariance models, we first tested single-factor models that treated mysticism as one factor instead of three. For the T1-T2 model, the onefactor configurative model had $\chi^{2}(\mathrm{df})=239.3$ (95), fitting worse than the 3 -factor configurative model $\Delta \chi^{2}=48$ (14), $p<.001$. For the T2-T3 model, the one-factor configurative model had $\chi^{2}=202.3$ (95), fitting marginally worse than the 3-factor model, $\Delta \chi^{2}(\mathrm{df})=23.5$ (14), $p=.052$. For the T1-T2-T3 model, the one-factor configurative model had $\chi^{2}=388.4$ (225), fitting worse than the 3-factor model $\Delta \chi^{2}(\mathrm{df})=64.9$ (33), $p<.001$.

| Table 2 |

\section{Test-retest reliability and convergent validity (H2)}

Table 3 displays the correlations of scale scores, below the diagonal, among three mysticism factors, religiosity, and spirituality measured across three times. Mysticism factors correlated more strongly with spirituality, $r s=.35$ to .69 , than with religiosity, $r \mathrm{~s}=.03$ to .44 . Religiosity and spirituality correlated positively with each other, $r s=.35$ to .38 . Bold terms above the diagonal are latent correlations of the same mysticism factor across time, estimated in the strict measurement invariance model—-these numbers ranging from .82 to .95 , suggesting strong test-retest reliability for the Mysticism Scale. H2 received support. 


\section{Moderation (H3)}

Religiosity at T1 predicted spirituality at T3, but the effects depended upon levels of mysticism measured. When mysticism was high, there was less effect of religiosity on spirituality. The moderation of extrovertive mysticism was significant, $b=-0.17, t=-3.47, p<$ .001 ; the moderation of interpretive mysticism was significant, $b=-0.14, t=-2.96, p=.003$; whereas the moderation of introvertive mysticism was not significant, $b=-0.06, t=-1.05, p=$ .298. Overall, there was a main effect of mysticism, such that people of higher mysticism would later report a higher level of spirituality. Figure 1 displays the moderation effects of extrovertive and interpretive mysticism. H3 received support.

\section{| Figure 1 |}

\section{Mediation (H4)}

The model in Figure 2 demonstrates that religiosity T1 predicted spirituality T3 $(b=0.36, t$ $=5.51, p<.001$ ), and the effect was partially mediated by the three T2 mysticism factors, with the remaining direct effect, $b=0.12, p=.030$. Specifically, the indirect effect on the path through introvertive mysticism was significant ( $b=0.07$ [95\% CI: .02, .14], $p=.031$ ); the indirect effect of extrovertive mysticism was not significant ( $b=0.00$ [95\% CI: $-.03, .03$ ], $p=.872$ ); the indirect effect of interpretive mysticism was significant ( $b=0.12$ [95\% CI: .05, .22], $p=.006)$.

Note that Figure 2 shows the estimated unstandardized coefficients in the path model. Interpretation of these numbers would follow that, for example of the top path .17, for one unit increase in Religiosity T1, there will be .17 increase in introvertive mysticism T2 (recall that all variables were measured on 1-5 Likert scales); and following this path further from introvertive mysticism T2 to spirituality T3, the coefficient of .41, multiplied with .17 from the first path, results in an indirect effect of .12 . 


\section{Discussion}

The results of our analyses support the hypothesis (H1) that the 8-item M-scale has measurement invariance across time and the structure and meaning of the items are stable across three times of measurement. Results also supported the hypothesis (H2) that the 8-item M-scale demonstrates test-retest reliability, and positive correlations with religiosity and spirituality document convergent validity. Results thus confirm the results in the previous study in which the development of the brief version of M-scale has been introduced and initially validated (Streib et al., 2020), but take these results further in adding much stronger evidence from three-wave longitudinal samples. Thus, the results of this study present strong support for the newly developed brief version of the M-Scale.

Also, analyses in this study offer empirical support for the separation of the three factors of the M-scale, thus lend support to the initial CFA with the new brief M-Scale (Streib et al., 2020), but also to the body of literature that has explored and confirmed the three-factor structure of the M-Scale (Hood et al., 1993; Hood et al., 2001; Lazar \& Kravetz, 2005; Chen, Hood et al., 2011; Chen, Qi et al., 2011; Chen, Zhang et al., 2012; Anthony et al., 2010; Klein et al., 2016).

For the investigation of the relation between mysticism and self-rated spirituality, this study tested a moderation model and a mediation model. Results supported the moderation hypothesis (H3) by demonstrating that mysticism (T2) moderates the effect of self-rated religiosity (T1) on self-rated spirituality (T3); the association between religiosity (T1) and spirituality (T3) is weaker among people high especially on interpretative mysticism. There is a moderation effect for extrovertive mysticism, however somewhat weaker, while the effect of introvertive mysticism was insignificant. In other words, considerably high self-rated spirituality (T3) was independent from self-rated religiosity (T1), if, and only if, interpretative mysticism was high at T2. High interpretative mysticism at T2 appears to predict high self-rated spirituality at T3, regardless whether a person is "highly spiritual ${ }_{\mathrm{T} 3}$, but low religious ${ }_{\mathrm{T} 1}$ " or "highly spiritual $\mathrm{T}_{\mathrm{T}}$ and highly 
religious $_{\mathrm{T} 1}$.” It is obvious that these results are in line with the findings reported by Hood (2003) from a cross-sectional study, where the highest levels of mystical experiences were reported by the group of the more spiritual than religious, and the two groups which included spirituality in their self-identifications (more spiritual than religious and equally religious and spiritual) were high in mysticism. The difference with the current study is that it allows to determine the direction of the (moderation) effect.

The other assumption regarding the relation of mysticism and self-rated spirituality was (H4) that mysticism (T2) mediates the prediction of self-rated religiosity (T1) on self-rated spirituality (T3). And results demonstrate that at least two factors of the M-Scale, interpretative mysticism and, somewhat weaker, introvertive mysticism, have mediating effects on self-rated spirituality. The results of this study regarding the outstanding role of the interpretative mysticism factor confirm previous estimates that were based on cross-sectional modeling (Klein et al., 2016; Streib et al., 2020). Therefore, we may conclude that experiences of perfection (positive affect), of sacredness, and of the revelation of a new view of reality (noetic quality) have outstanding mediating and predictive effects on self-rated spirituality. Regarding the other two M-Scale factors, this study documents an effect, albeit weaker, for introvertive mysticism, while in previous modeling introvertive mysticism was not significant and extrovertive mysticism had a negative effect, if any. Here we conclude with the desideratum for further research about the differences in M-Scale factors for predicting and mediating effects on self-rated spirituality.

Taken together, the fact that both hypotheses (H3; H4) have received support from the three-wave longitudinal data adds considerable evidence to the assumption that mysticism, and strongest the factor of interpretative mysticism, and self-rated spirituality are related. This study thus confirms previous findings on the basis of cross-sectional data such as Zinnbauer et al. 's (1997) and Hood's (2003) studies, and also findings based on the data of Spirituality Study (Streib \& Hood, 2016b) such as Klein et al.’s (2016) modeling and modeling with the full and the brief 
version of the M-Scale (Streib et al., 2020). What qualifies the results presented in this study as major step forward, is the fact that they are based on three-wave longitudinal data, which allow for the directional assessment and estimation of predicting effects.

For the results based on the three-wave data, especially the moderation and meditation analyses, we should note a limitation however: The three-wave sample includes 83.5\% German participants. This needs to be considered when interpreting our results: While these analyses clearly indicate the effects of mystical experiences on self-rated spirituality for German participants, satisfactory confidence that this is true for US participants is expected from results in future studies. And for the same reason the relatively small portion of US participants did not allow for cross-cultural comparison.

\section{Conclusion}

There are two conclusions from this study: First, the results of this study present strong support for the newly developed brief 8-item version of the M-Scale and its suitability in research, when questionnaire length is an issue. Second, this study adds evidence to the proposition that mysticism as measured with the M-Scale-in this case, the newly developed short 8-item version of the M-Scale—clearly relates to self-rated spirituality, since self-reported mystical experiences moderate and partially mediate the effects of self-rated religiosity on self-rated spirituality.

One task for future research would be the attempt to clarify the differences between the three M-Scale factors in predicting, moderating, and mediating self-rated spirituality. Also, a more comprehensive model for an explanation of people's preference for self-rated spirituality is desirable, which should consider additional predictors such as personality, values, attachment or socialization and biographical change, including (critical) life events such as deconversion experiences. Regarding the latter, the sample that was used for the mediation model includes about $50 \%$ participants who have been interviewed three times with the faith development interview and thus will allow for complementing the nomothetic modeling with idiographic and idiothetic 
evaluation of their religious/spiritual development over the course of a decade. This would be too much to report in one article; there is more to come.

\section{References}

Anthony, F.-V., Hermans, C. A. M., \& Sterkens, C. (2010). A comparative study of mystical experience among Christian, Muslim, and Hindu students in Tamil Nadu, India. Journal for the Scientific Study of Religion, 49(2), 264-277.

Bourdieu, P. (1971a). Gènese et structure de champ religieux. Revue fraiçais de Sociologie, XII, 295334.

Bourdieu, P. (1971b). Une interprétation de la théorie de la religion selon Max Weber. Archives européennes de sociologie, 12(1), 3-21.

Chen, Z., Hood, R. W., Yang, L., \& Watson, P. J. (2011). Mystical experience among Tibetan Buddhists: The common core thesis revisited. Journal for the Scientific Study of Religion, 50(2), 328-338. https://doi.org/10.1111/j.1468-5906.2011.01570.x.

Chen, Z., Qi, W., Hood, R. W., \& Watson, P. J. (2011). Common core thesis and qualitative and quantitative analysis of mysticism in Chinese Buddhist monks and nuns. Journal for the Scientific Study of Religion, 50(4), 654-670. https://doi.org/10.1111/j.14685906.2011.01606.x.

Chen, Z., Zhang, Y., Hood, R. W., \& Watson, P. J. (2012). Mysticism in Chinese Christians and nonChristians: Measurement invariance of the Mysticism Scale and implications for the mean differences. International Journal for the Psychology of Religion, 22(2), 155-168. https://doi.org/10.1111/j.1468-5906.2011.01570.x. 
Daiber, K.-F. (2002). Mysticism: Troeltsch's third type of religious collectivities. Social Compass, 49(3), 329-341, https://doi.org/10.1177/0037768602049003002.

Hood, R. W. (1975). The construction and preliminary validation of a measure of reported mystical experience. Journal for the Scientific Study of Religion, 14, 29-41.

Hood, R. W. (2003). The relationship between religion and spirituality. In A. L. Greil \& D. G. Bromley (Eds.), Defining religion: Investigating the boundaries between the sacred and the secular (pp. 241-265). Elsevier Science.

Hood, R. W., Ghorbani, N., Watson, P. J., Ghramaleki, A. F., Bing, M. N., Davison, H. K., Morris, R. J., \& Williamson, W. P. (2001). Dimensions of the Mysticism Scale: Confirming the three-factor-structure in the United States and Iran. Journal for the Scientific Study of Religion, 40(4), 691-705. https://doi.org/10.1111/0021-8294.0008.

Hood, R. W., Hill, P. C., \& Spilka, B. (2018). The psychology of religion: An empirical approach (5th ed.). Guilford Press.

Hood, R. W., Morris, R. J., \& Watson, P. S. (1993). Further factor-analysis of Hood's Mysticism Scale. Psychological Reports, 73(3), 1176-1178. https://doi.org/10.2466/pr0.1993.73.3f.1176.

James, W. (1902). The varieties of religious experience. A study in human nature. Random House, 1994.

Klein, C., Silver, C. F., Coleman, T. J., Streib, H., \& Hood, R. W. (2016). "Spirituality" and mysticism. In H. Streib \& R. W. Hood (Eds.), Semantics and psychology of "spirituality". A cross-cultural analysis (pp. 165-187). Springer International Publishing Switzerland. https://doi.org/10.1007/978-3-319-21245-6_11.

Kline, R. B. (2016). Principles and practice of structural equation modeling, 4th ed.. Guilford Press.

Lazar, A., \& Kravetz, S. (2005). Responses to the mystical scale by religious Jewish persons: A 
comparison of structural models of mystical experience. International Journal for the Psychology of Religion, 15(1), 51-61. https://doi.org/10.1207/s15327582ijpr1501_4.

Stace, W. T. (1960). Mysticism and philosophy. J.B. Lippincott Company.

Streib, H. (2005). Research on life style, spirituality and religious orientation of adolescents in Germany. In L. J. Francis, M. Robbins, \& J. Astley (Eds.), Religion, education and adolescence: International and empirical perspectives (pp. 131-163). University of Wales Press.

Streib, H., \& Hood, R. W. (2011). "Spirituality" as privatized experience-oriented religion: Empirical and conceptual perspectives. Implicit Religion, 14(4), 433-453. https://doi.org/10.1558/imre.v14i4.433

Streib, H., \& Hood, R. W. (2013). Modeling the religious field: Religion, spirituality, mysticism and related world views. Implicit Religion, 16(3), 137-155. https://doi.org/10.1558/imre.v16i2.137

Streib, H., \& Hood, R. W. (2016a). Understanding "spirituality" - Conceptual considerations. In H. Streib \& R. W. Hood (Eds.), Semantics and psychology of "spirituality". A cross-cultural analysis (pp. 3-17). Springer International Publishing Switzerland, https://doi.org/10.1007/978-3-319-21245-6_1.

Streib, H., \& Hood, R. W. (Eds.). (2016b). Semantics and psychology of spirituality. A crosscultural analysis. Springer International Publishing Switzerland.

Streib, H., Hood, R. W., Keller, B., Csöff, R.-M., \& Silver, C. (2009). Deconversion. Qualitative and quantitative results from cross-cultural research in Germany and the United States of America. Vandenhoeck \& Ruprecht.

Streib, H., Klein, C., Keller, B., \& Hood, R. W. (2020). The Mysticism Scale as measure for 
subjective spirituality: New results with Hood's M-Scale and the development of a short form. In A. L. Ai, K. A. Harris, \& P. Wink (Eds.), Assessing spirituality and religion in a diversified world. Springer International Publishing Switzerland.

Troeltsch, E. (1912). The social teaching of the Christian churches, Vol. 2. George Allen \& Unwin; MacMillan, 1956.

Weber, M. (1921). Religious groups (Sociology of Religion). In G. Roth \& C. Wittich (Eds.), Max Weber economy and society (pp. 399-634). University of California Press, 1978.

Zinnbauer, B. J., Pargament, K. I., Cole, B., Rye, M. S., Butter, E. M., Belavich, T. G., Hipp, K.M., Scott, A.B., \& Kadar, J. L. (1997). Religion and spirituality: Unfuzzying the fuzzy. Journal for the Scientific Study of Religion, 36(4), 549-564. 
Table 1. Measurement invariance models across time.

\begin{tabular}{|c|c|c|c|c|c|c|c|c|}
\hline & $\chi^{2}(\mathrm{df})$ & RMSEA & CFI & SRMR & $\overline{\mathrm{BIC}}$ & Model Comparison & $\triangle \mathrm{RMSEA}$ & $\triangle \triangle \mathrm{CFI}$ \\
\hline \multicolumn{9}{|c|}{ Cross-Time Invariance across Time 1 and Time $2(N=287)$} \\
\hline 1. Configural Invariance & $191.3(81)$ & .069 & .960 & .041 & 14678 & & & \\
\hline 2. Weak Invariance & 195.8(86) & .067 & .960 & .044 & 14655 & 2 vs. 1 & -.002 & .000 \\
\hline 3. Strong Invariance & 230.8(94) & .071 & .951 & .045 & 14735 & 3 vs. 2 & .004 & -.009 \\
\hline 4. Strict Invariance & 237.1(102) & .068 & .951 & .045 & 14696 & 4 vs. 3 & -.003 & .000 \\
\hline \multicolumn{9}{|c|}{ Cross-Time Invariance across Time 2 and Time $3(N=230)$} \\
\hline 1. Configural Invariance & $178.8(81)$ & .072 & .960 & .045 & 11631 & & & \\
\hline 2. Weak Invariance & $181.4(86)$ & .069 & .961 & .047 & 11606 & 2 vs. 1 & -.003 & .001 \\
\hline 3. Strong Invariance & 201.2(94) & .070 & .956 & .047 & 11670 & 3 vs. 2 & .000 & -.005 \\
\hline 4. Strict Invariance & 223.2(102) & .072 & .950 & .048 & 11648 & 4 vs. 3 & .002 & -.006 \\
\hline \multicolumn{9}{|c|}{ Cross-Time Invariance across Time 1, Time 2 , and Time $3(N=158)$} \\
\hline 1. Configural Invariance & 323.5(192) & .066 & .955 & .053 & 11747 & & & \\
\hline 2. Weak Invariance & 328.3(202) & .063 & .957 & .055 & 11701 & 2 vs. 1 & -.003 & .002 \\
\hline 3. Strong Invariance & 369.7(218) & .066 & .948 & .056 & 11783 & 3 vs. 2 & .003 & -.009 \\
\hline 4. Strict Invariance & 396.3(234) & .066 & .945 & .056 & 11729 & 4 vs. 3 & .000 & -.003 \\
\hline
\end{tabular}

All chi-square tests are significant with $p<.001$. 
Table 2. Standardized loadings of the 8-item Mysticism Scale items in confirmatory factor analysis with strict invariance constrained across three times.

1. I have had an experience which was both timeless and spaceless

2. I have had an experience in which something greater than myself seemed to absorb me

3. I have had an experience in which I realized the oneness of myself with all things

4. I have had an experience in which a new view of reality was revealed to me

5. I have had an experience in which I felt that all was perfection at the time

6. I have had an experience which I knew to be sacred

7. I have had an experience in which all things seemed to be conscious

8. I have had an experience which cannot be expressed in words
Introvertive Extrovertive Interpretive

.797

.805

.782

.786

.682

Key for scoring the three factors of mysticism: Introvertive Mysticism - 1, 2, 8; Extrovertive Mysticism - 3, 7; Interpretive Mysticism - 4, 5, 6. No reverse scoring is needed. 
Table 3. Correlations and descriptive statistics of three mysticism factors, religiosity, and spirituality measured at T1 $(N=1886)$, T2 $(N=710)$, and T3 $(N=478)$.

\begin{tabular}{|c|c|c|c|c|c|c|c|c|c|c|c|c|c|c|c|}
\hline & int1 & int2 & int3 & ext1 & ext2 & ext3 & itp1 & itp2 & itp3 & rel1 & rel2 & rel3 & spr1 & spr2 & spr3 \\
\hline$\overline{\text { int1 }}$ & .74 & .85 & .76 & & & & & & & & & & & & \\
\hline int2 & .74 & .76 & .95 & & & & & & & & & & & & \\
\hline int3 & .65 & .75 & .80 & & & & & & & & & & & & \\
\hline ext1 & .57 & .57 & .55 & .66 & .94 & .82 & & & & & & & & & \\
\hline ext2 & .58 & .63 & .61 & .66 & .64 & .94 & & & & & & & & & \\
\hline ext3 & .60 & .58 & .68 & .71 & .71 & .74 & & & & & & & & & \\
\hline itp1 & .67 & .71 & .67 & .64 & .58 & .62 & .69 & .88 & .86 & & & & & & \\
\hline itp2 & .63 & .69 & .69 & .57 & .63 & .57 & .79 & .74 & .85 & & & & & & \\
\hline itp3 & .61 & .64 & .77 & .61 & .56 & .73 & .77 & .77 & .74 & & & & & & \\
\hline rel1 & .19 & .25 & .21 & .03 & .12 & .12 & .24 & .33 & .29 & -- & & & & & \\
\hline rel2 & .31 & .34 & .25 & .17 & .13 & .07 & .35 & .42 & .33 & .76 & -- & & & & \\
\hline rel3 & .31 & .32 & .30 & .32 & .19 & .14 & .40 & .44 & .37 & .74 & .84 & -- & & & \\
\hline spr1 & .54 & .58 & .59 & .39 & .44 & .58 & .57 & .64 & .65 & .37 & .42 & .45 & -- & & \\
\hline spr2 & .58 & .55 & .57 & .45 & .44 & .55 & .61 & .61 & .63 & .35 & .47 & .44 & .79 & -- & \\
\hline spr3 & .59 & .63 & .59 & .53 & .51 & .53 & .67 & .69 & .64 & .38 & .45 & .53 & .77 & .81 & - \\
\hline$M$ & 3.58 & 3.30 & 3.40 & 3.16 & 2.85 & 2.85 & 3.52 & 3.11 & 3.18 & 2.59 & 2.44 & 2.67 & 3.76 & 2.98 & 3.27 \\
\hline$S D$ & 1.11 & 1.14 & 1.20 & 1.24 & 1.24 & 1.36 & 1.12 & 1.20 & 1.26 & 1.50 & 1.39 & 1.50 & 1.39 & 1.39 & 1.46 \\
\hline
\end{tabular}

Note: Cronbach's alpha values are the italicized numbers on the diagonal. Bold terms above the diagonal are latent correlations in the CFA model with strict measurement invariance across three times. Below diagonal are correlations of scale scores. Shorthand labels are: int = Introvertive Mysticism; ext = Extrovertive Mysticism; itp = Interpretive Mysticism; rel = Self-Reported Religiosity; spr = Self- Reported Spirituality. Numbers at the end of each shorthand indicate measurement. For instance, int1 = introvertive mysticism at time 1. 

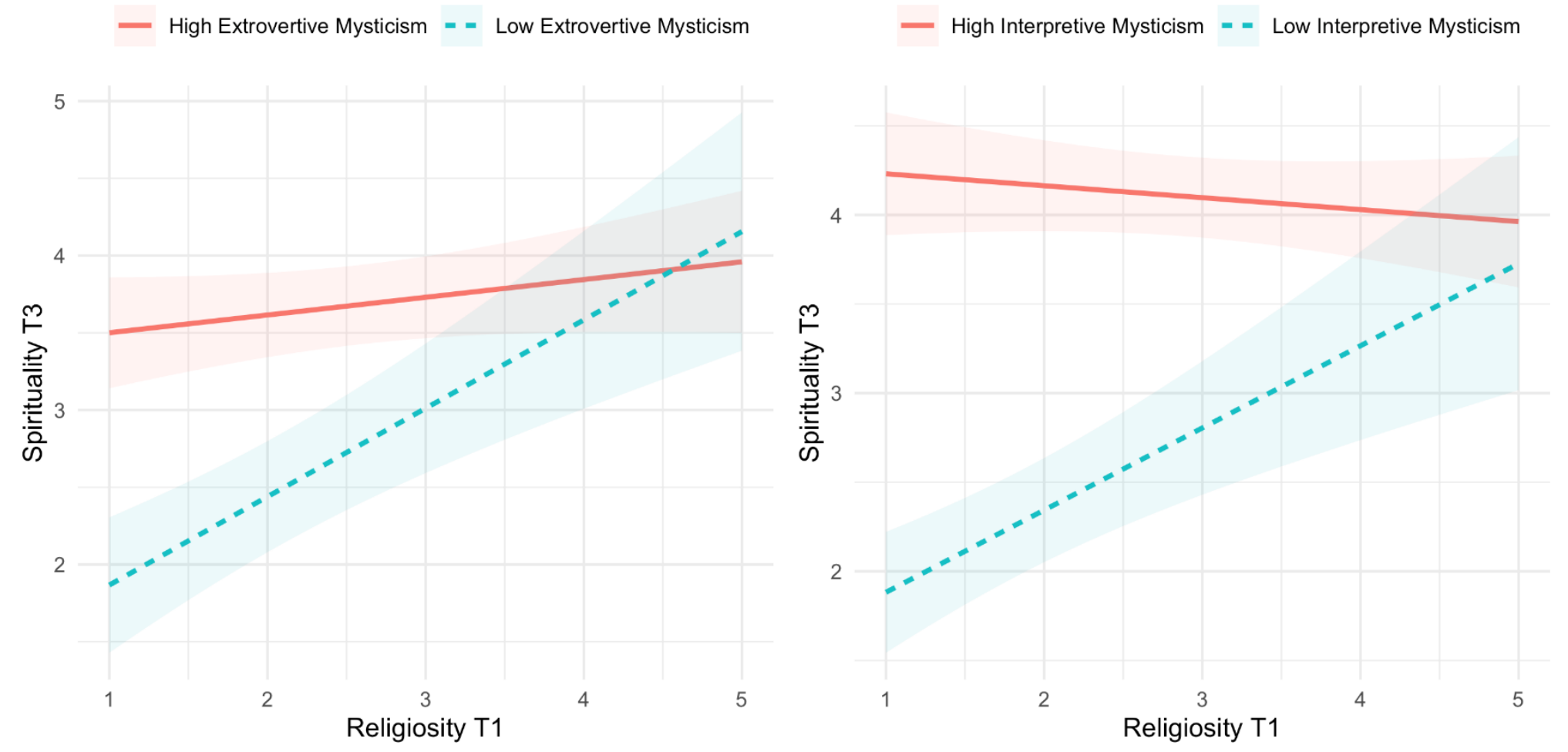

Figure 1. Moderation effect of extrovertive and interpretive mysticism on the association of self-reported religiosity and spirituality. 


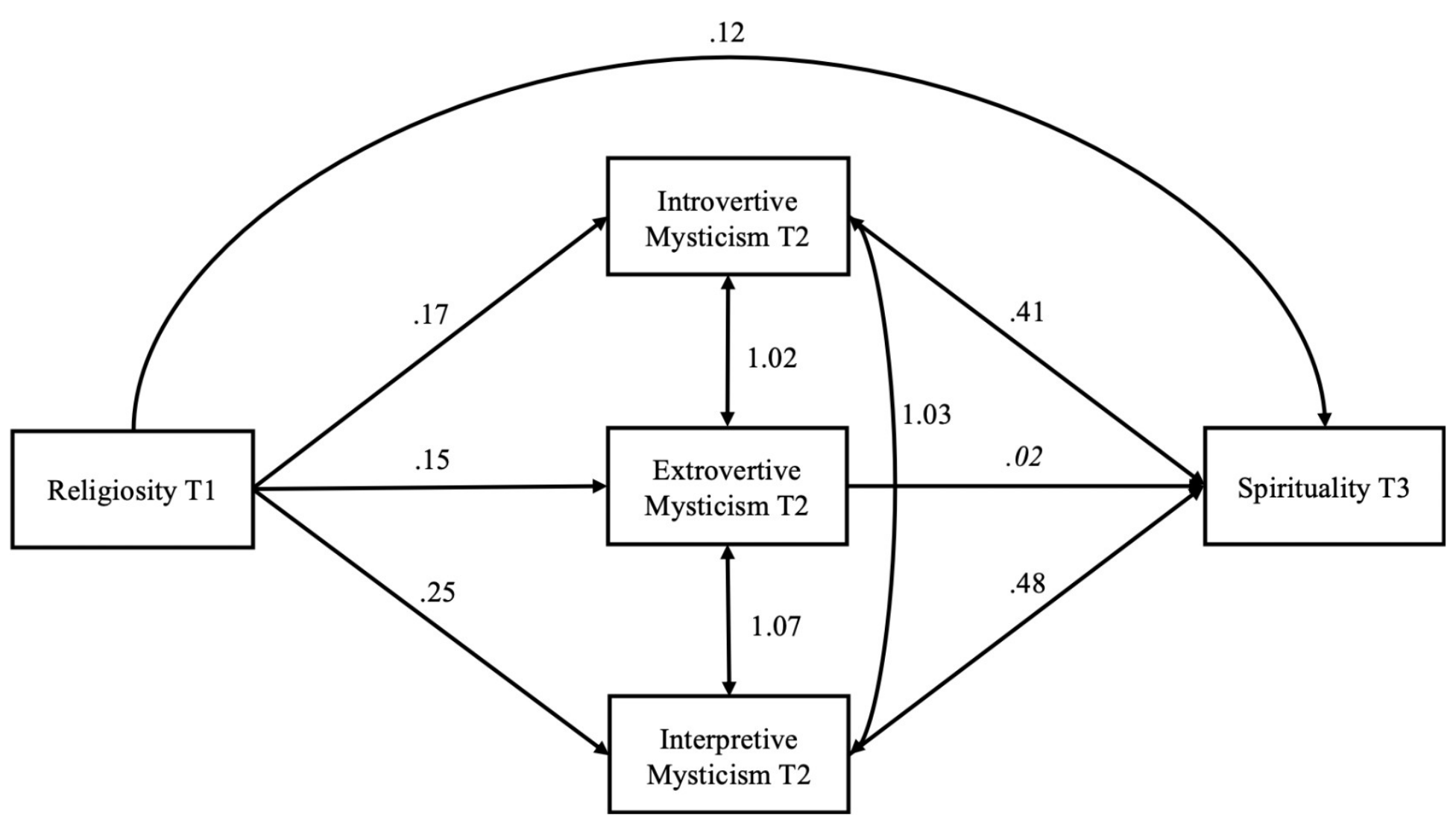

Figure 2. Mediation effect of mysticism factors on the association of religiosity and spirituality displayed with unstandardized path coefficients. All paths were significant except the italicized one. 